\title{
Problematizando a produção da vulnerabilidade e da pobreza higienizada na Assistência Social
}

\author{
Keli Lopes Santos' \\ Prefeitura Municipal de Santa Maria de Jetibá, ES, Brasil \\ Ana Lucia Coelho Heckert \\ Universidade Federal do Espírito Santo, ES, Brasil
}

\begin{abstract}
Resumo: Com este artigo, temos como objetivo discutir como vêm se efetuando atualmente os processos de resistências e de regulamentação da vida nos Centros de Referência da Assistência Social (Cras). Especificamente, almejamos discutir como as noções de vulnerabilidade e higienização têm sido instrumentalizadas para o controle. Os conceitos de Resistência e Regulamentação da Vida de Foucault são as principais ferramentas conceituais. Nesta pesquisa, foram utilizadas duas principais estratégias de produção de saber: análise das anotações e das memórias da pesquisadora e análise do material de novas conversas individuais e grupais com usuárias, profissionais e ex-profissionais dos Cras do município de Cariacica, no Espírito Santo. Observou-se que rotular essa população como vulnerável ou em risco contribui para sua estigmatização e para justificar uma série de intervenções higienistas. No entanto, é possível notar que muitas dessas pessoas/grupos não aceitam e escapam dessas intervenções em um exercício de resistência e afirmação de modos de vida contra-hegemônicos.
\end{abstract}

Palavras-chave: assistência social; vulnerabilidade; higienização; regulamentação da vida; controle.

\section{PROBLEMATIZING THE PRODUCTION OF VULNERABILITY AND "HYGIENED" POVERTY IN SOCIAL ASSISTANCE}

\begin{abstract}
This article aims at discussing how resistance processes and regulation of life in the Social Assistance Reference Centers (SARC) is carried out, specifically how the notions of vulnerability and hygiene have been instrumented to control things. Michel Foucault's concepts of Resistance and Regulation of Life are the main conceptual tools. In this research, we have deployed two main knowledge production strategies: the analysis of the researcher's notes and memories and the analysis of new individual e group conversations with SARC users, professionals, and ex-professionals from Cariacica, in Espírito Santo. We have observed that labeling the population as vulnerable or at risk contributes to their stigmatization and to justify a series of interventions that seek "to hygiene" them. However, it is worth noting many of these people/groups do not accept and tend escape these interventions in an exercise of resistance and affirmation of counter-hegemonic ways of life.
\end{abstract}

Keywords: social assistance policy; vulnerability; "to hygiene"; regulation of life; control.

1 Endereço para correspondência: Keli Lopes Santos. Rua Mateus Corteletti, 11, Nova América, Vila Velha, ES, CEP 29.111-850. Telefone: E-mail: kelilopes@gmail.com 


\begin{abstract}
Resumen: En este artículo propone discutir cómo es que está realizando actualmente los procesos de resistencia y procesos de regulación de la vida en los Centros de Referencia de Asistencia Social (Cras). Específicamente cómo las nociones de vulnerabilidad e higiene han sido manipuladas por el control. Los conceptos de resistencia y regulación de la vida de Michel Foucault son las principales herramientas conceptuales. En esta investigación se utilizaron dos principales estrategias de producción de saber: análisis de las anotaciones y memorias de la investigadora y análisis del material de nuevas conversaciones individuales y grupales con usuarias, profesionales y ex profesionales de los Cras del municipio de Cariacica, en Espírito Santo. Se observó que el etiquetado de la población depende de esta política como vulnerables o en riesgo contribuye a su estigma y buscan sanear esta población. Sin embargo, se puede ver que muchas de estas personas / grupos no aceptan y escapar estas intervenciones en un ejercicio de resistencia y afirmación de formas contra hegemónicas de la vida.
\end{abstract}

Palabras clave: asistencia social; vulnerabilidad; saneamiento; regulación de la vida; control.

\title{
Introdução - A assistência social no Brasil: entre controles e resistências
}

Os princípios da Política Nacional de Assistência Social (PNAS) postulam que essa política está direcionada a quem dela necessitar (Brasil, 2004). Quem necessita da política de assistência social? Com vários recortes de renda para acesso aos benefícios, essa política acaba sendo direcionada para a parcela da população que se tornou pobre, ou seja, para aqueles que têm dificuldade de garantir os próprios direitos pela inserção no mercado. A essas pessoas tem sido direcionado o rótulo de vulneráveis ou em risco.

Foi no Plano Nacional de Assistência Social, criado a partir da IV Conferência da Assistência Social de 2003, que se apontou para a criação de um Sistema Único de Assistência Social (Suas) no Brasil. Nesse Plano já se observa um direcionamento para a estruturação dos serviços da Assistência Social entre Proteção Social Básica e Especial, além do direcionamento para a consolidação do Programa de Atenção Integral à Família (Paif) (Brasil, 2004). Foi então, em 2005, que foi aprovada a criação do Suas, uma política de caráter descentralizado e participativo, a exemplo do Sistema Único de Saúde (SUS).

Atualmente, as regulamentações federais citadas anteriormente preveem que nos Cras devem ser realizadas ações que possuem objetivo de proteção social, fortalecimento de vínculos familiares e comunitários e prevenção de seu rompimento, bem como promoção do acesso aos benefícios socioassistenciais.

Nesse contexto, visamos, neste artigo, analisar como os conceitos de vulnerabilidade e de risco têm operado para a regulamentação da vida das pessoas que buscam os serviços dos Centros de Referência da Assistência Social (Cras). Quando falamos em regulamentação da vida, aludimos ao conceito elaborado por Foucault (2005a) ao se referir a um modo de exercício do poder que atua por meio de mecanismos globais sobre a população para se obter estados de regularidade e controle, diferenciando-se do poder disciplinar que atua sobre o corpo dos indivíduos. Para Foucault (2008b, p. 124), não existe "o" poder, e sim múltiplos regimes de governamentalidade "[...] já que muita 
gente governa: o pai de família, o superior de um convento, o pedagogo e o professor em relação à criança e ao discípulo [...] todos esses governos são interiores à própria sociedade ou ao Estado".

Para falar de regulamentação da vida e governamentalidade, no entanto, é primordial que se entenda o conceito de resistência desse mesmo autor para que não se caia no fatalismo de pensar que não há saídas para os mecanismos de controle instituídos. Foucault (2010b, p. 276) sinaliza, portanto, que é por meio das práticas de resistência que será possível elucidar as relações de poder, "[...] localizar sua posição, descobrir seu ponto de aplicação e os métodos empregados. [...] para descobrir o que significa [...] a sanidade, talvez devêssemos investigar o que ocorre no campo da insanidade". Ou seja, é primordial destacar que não existe relação de controle sem resistência ou escapatória. Como afirma Foucault (2010b), a resistência é primeira; justamente porque existem desvios é que há investimento de controle. E é por isso que se mostra relevante dar ouvidos a esses exercícios de resistência.

\section{Estratégias para a produção de saber}

Faremos uso do termo "estratégias de produção de saber" em detrimento do termo "método". Essa mudança se mostra necessária quando assumimos que método e problema de pesquisa não se encontram em lados opostos, mas estão mutuamente relacionados. Nessa perspectiva, não existe uma realidade pronta e independente do nosso modo de acesso a ela, portanto, não existe um método privilegiado de acesso a essa realidade (Silva, 2005).

Este artigo derivou de uma dissertação de mestrado em que foram utilizadas duas principais estratégias de produção de saber. Uma delas foi a análise das anotações e das memórias da pesquisadora, incluindo principalmente: 1) o trabalho realizado em três Cras na região metropolitana de Vitória, Espírito Santo, entre os anos 2010 e 2012; 2) a militância no Fórum Estadual dos Trabalhadores do Sistema Único da Assistência Social do Espírito Santo, de 2010 a 2013, e no Conselho Estadual de Assistência Social do Espírito Santo, de 2013 a 2014; 3) a atuação no Projeto de Extensão da Universidade Federal do Espírito Santo intitulado "Redes de Políticas no Território". Outra estratégia foi a análise de novas conversas individuais e em grupos realizadas com usuárias, profissionais e ex-funcionárias dos Cras do município de Cariacica, no Espírito Santo, no período de julho a novembro de 2014. Essa pesquisa contou com submissão ao comitê de ética em pesquisa, que aprovou a proposta.

Inúmeras são as histórias de práticas de resistências que infelizmente não poderão ser incluídas neste texto, para não expor em demasia as armas e as estratégias dos guerrilheiros das lutas cotidianas, e para não fazer desta produção de saber conteúdo de judicialização da ação de profissionais e usuários. Já que alguns movimentos de resistência são passíveis de coerção e punição, assim também se faz resistência. Nesse sentido, este texto pode ser considerado mais um dispositivo dessas lutas cotidianas. Ao 
mesmo tempo, as práticas de regulamentação da vida ganharam densidade exatamente para dar visibilidade aos processos de controle e regulamentação da vida que estamos operando nas políticas públicas dirigidas às camadas mais pobres da população.

Ao utilizar a experiência do pesquisador como uma estratégia de produção do saber, apontamos um processo de constituição de si, uma escrita de si, como apontou Foucault (2006a). A experiência é algo do qual saímos transformados (Foucault, 2010a), é ação que nos convoca a um exercício ético indagador das evidências que nos fabricam como sujeitos. A utilização das memórias teve nesse trabalho o objetivo de colocar em análise as nossas implicações (Lourau, 2004) com as instituições que atravessam e delineiam nosso mandato profissional, por vezes nos fazendo operar de maneira endurecida e atuar em nome do Estado, frequentemente fazendo alianças com práticas inusitadas de afirmação da vida.

A revisão bibliográfica foi realizada com o objetivo de problematizar e desnaturalizar conceitos que passaram a operar no âmbito da governamentalidade em determinados contextos históricos, principalmente as noções de vulnerabilidade, risco e periculosidade. Com isso, por um lado, não se tem a pretensão de constituir "a" história desses conceitos ou precisar seu surgimento em termos cronológicos. Por outro, pretende-se fazer história para desestabilizar o presente, para evidenciar que tudo que se apresenta como natural, óbvio e necessário foi construído e, assim como aponta Foucault (2006b), para produzir instrumentos de análise, de intervenção política e de ação sobre a realidade e sobre nós mesmos.

\section{Resultados e Discussão - Vulnerabilidade em questão}

Nos Serviços da Assistência Social, para que sejam disponibilizados benefícios é necessário que o indivíduo seja enquadrado em situação de vulnerabilidade, como também avaliaram Siqueira \& Lino (2013). Quais são os efeitos de ser considerado em vulnerabilidade?

Uma profissional relatou que seu primeiro emprego como profissional de nível superior foi em um Cras. Foi orientada por sua coordenadora sobre o trabalho do Paif, sendo afirmado que as famílias atendidas eram aquelas com maior risco entre as demais, e que, portanto, deveriam ser acompanhadas. Contudo, a conversa não a esclareceu o que era o conceito de risco e ela ficou pensando: afinal, o que seria esse risco? O conceito de risco ou vulnerabilidade atribuído às famílias que buscam os serviços da Assistência Social merece destaque, uma vez que essa noção é naturalizada no cotidiano de trabalho dos serviços e nas orientações federais. Estão em situação de vulnerabilidade social, de acordo com as normativas federais,

[...] aqueles que estão em condições precárias ou privadas de renda e sem acesso aos serviços públicos (dimensão material da vulnerabilidade) e aqueles cujas características sociais e culturais (diferenças) são desvalorizadas ou discriminadas negativamente (dimensão relacional da vulnerabilidade) (MDS, 2013, p. 7). 
A Proteção Social tem por objetivo eliminar/minimizar situações de privação material e discriminação negativa por meio de serviços continuados, capazes de desenvolver potencialidades e assegurar aquisições, além de fortalecer vínculos familiares e vínculos sociais mais amplos necessários ao exercício da cidadania (MDS, 2013, p. 8). Também se afirma a necessidade de fortalecimento de vínculos, já que existem "[...] convivências que desprotegem e tornam as pessoas mais vulneráveis" (MDS, 2013, p. 12). A esse respeito, Cruz \& Hillesheim (2013, p. 186 e 187, grifo das autoras) avaliam que "[...] nessa formulação está implícito que há formas de conviver melhor que outras, tanto que um dos serviços do PAIF são os grupos de convivência [...]".

É possível notar que as orientações federais fazem uso do termo vulnerabilidade a partir da contribuição de autores que a consideram como "[...] o resultado da confluência da exposição aos riscos, da incapacidade de resposta e da inabilidade de adaptação" (MDS, 2013, p. 25). Ou ainda vinculam a vulnerabilidade "[...] à pobreza, em decorrência da grande quantidade de movimentos de entrada e saída dessa condição [...]" (MDS, 2013, p. 26). Essas recomendações federais admitem que "[...] a falta de equidade socioeconômica e as precárias condições socioambientais do território são consideradas riscos, pois obstruem o desenvolvimento socioeconômico e impedem a coesão social" (MDS, 2013, p. 26).

Como apontam Siqueira \& Lino (2013, p. 47), "[...] nomear as famílias como 'em risco' e 'em vulnerabilidade' torna-se uma forma de desqualificar essas diferenças e de afirmar a importância da intervenção das profissionais em suas vidas, prescrevendo formas de ser e de viver". A desobediência a essas prescrições nesse contexto também é encarada como "risco" que deve então ser erradicado e até mesmo punido. Siqueira \& Lino (2013, p. 47) apontam a importância de observarmos esses chamados "fatores de risco" sob outro aspecto: "A vida é um risco, sobretudo se criamos, se inventamos novas formas de viver, se rompemos com o instituído, com a norma". Participar do acompanhamento familiar no Cras, portanto, diz respeito também a se submeter a determinadas regras que visam um controle apurado da vida. Não participar desse processo pode indicar uma tentativa de garantir que se possa viver de diferentes modos, não necessariamente os determinados pelas políticas estatais. A não participação pode ser expressão de um processo de resistência.

Outra estratégia de escape observada entre as usuárias foi a "trapaça" nas senhas distribuídas nos Cras. Durante conversas com profissionais, elas dizem que frequentemente produzem senhas em papel de cores diferentes de acordo com o dia para cada tipo de atendimento/demanda. Explicam que diariamente são distribuídas senhas para os diferentes tipos de atendimento no Cras, já que a demanda é maior do que a capacidade diária de atendimentos, e que as usuárias por vezes aparecem com a senha para outros tipos de atendimentos. Dizem ainda que muitas usuárias levam a senha para casa em determinado dia e retornam em outro com a mesma senha, burlando a organização do Cras, ou pegam senha para o vizinho ir outro dia. Afirmam que fazem as senhas de cores diferentes para terem o controle de quem realmente 
compareceu no dia, já que existe um número limitado de senhas distribuídas por dia para a marcação de atendimentos.

Portanto, o mecanismo de resistência ficou evidente pela prática de controle, no caso, a manufatura de diferentes senhas de papel para os atendimentos. Nota-se que a construção dessas senhas diz respeito a uma tentativa de gestão do processo de trabalho já que existe limitação da capacidade de atendimentos. Observa-se, com isso, ser necessário retirar as trapaças realizadas pelas usuárias do campo dos julgamentos morais e entendê-las em um contexto de necessidade ante a falta de capacidade adequada de atendimento para todos. Estratégias inventivas e de generosidade são criadas para se conseguir atendimento.

Quando trabalhava no Cras, a gestão municipal providenciou crachás para as trabalhadoras, como preconizado pelas legislações da Assistência Social, já que é um direito da usuária saber a credencial de quem as atende. Muitas profissionais se manifestaram contrárias a essa iniciativa, afirmando que as usuárias iriam se utilizar de forma prejudicial e criminosa das informações das profissionais contidas no crachá. Ora, o que justifica essa relação de extrema desconfiança em relação às usuárias? Curioso é observar que as usuárias, para serem atendidas e receberem os benefícios, devem apresentar todos os seus documentos às profissionais. Nesse caso, alguma profissional também poderia fazer uso mal-intencionado ou criminoso dos dados das usuárias. Por que a desconfiança só recai sobre as usuárias?

Com objetivo de desnaturalizar essas noções de risco e periculosidade, nos serviremos das contribuições de Foucault (2008a; 2005b). O autor aponta que a noção de risco, bem como a noção de perigo foram gestadas ao longo dos séculos XVII e XVIII, possibilitando a criação de um olhar diferenciado sobre a população. Avalia que no século XVII tinha-se a ideia de "doença reinante", como a varíola, a qual se caracterizava como aquilo que se efetivava de acordo com a região, modos de vida, clima, cidade. "Era nessa relação maciça e global entre um mal e um lugar, um mal e pessoas, que se definia, se caracterizava a doença reinante" (Foucault, 2008a, p. 79). Em determinado momento, em contraponto, a doença vai aparecer como uma distribuição de casos em uma população que será delimitada no tempo ou no espaço, e a partir disso será possível identificar e controlar os riscos (Foucault, 2008a), promovendo gestão da vida.

A noção de risco torna-se central e seu cálculo logo deixará evidente que os riscos não são os mesmos para cada indivíduo ou grupo, faixa etária, condições de vida etc. Essa diferenciação revela zonas de maiores ou de menores riscos. Desse modo, pode-se identificar o que é perigoso (Foucault, 2008a). Essa nova governamentalidade operará por distribuições diferenciadas que também justificarão inclusões diferenciadas. Foucault (2008a) identifica ainda que todo esse novo sistema e essas novas noções passam a integrar os mecanismos de segurança da população, de forma a constituir, por meio da instrumentação do saber econômico, " [...] uma sociedade controlada por dispositivos de segurança" (Foucault, 2008b, pp. 145-146). De acordo com o autor, "esses mecanismos também tendem a uma anulação dos fenômenos, não na forma da 
proibição, 'você não pode fazer isso', [...] Trata-se [...] de delimitá-los em marcos aceitáveis, em vez de impor-lhes uma lei que lhes diga não" (Foucault, 2008a, p. 86).

A noção de periculosidade, por sua vez, foi criada no século XIX (Foucault, 2005b). Por meio dela, o indivíduo passou a ser considerado ao nível de suas virtualidades, e não de seus atos em si. Essa noção, que era utilizada no âmbito do Poder Judiciário, começou a ser executada também por outros poderes laterais; ela requer permanente vigilância sobre os indivíduos por alguém que exerce sobre eles um poder. Enquanto se exerce esse poder, há também a possibilidade de se produzir um saber sobre os vigiados. Esse novo saber "[...] se ordena em torno da norma, em termos do que é normal ou não, correto ou não, do que se deve ou não fazer" (Foucault, 2005b, p. 88). Foucault (2005b) avalia que essa é a base da forma de saber-poder exercida pelas ciências humanas: Psiquiatria, Psicologia, Sociologia, por exemplo.

Vale destacar que o Cras possui como um de seus objetivos primeiros a prevenção. Porém, essas ações possuem eficácia duvidosa, de acordo com Castel (2005), pois essa busca à prevenção e à segurança pode se transformar em busca a bodes expiatórios: "O fantasma de 'novas classes perigosas' constituídas pelos jovens das periferias exemplifica este tipo de derrapagem" (Castel, 2005, p. 91). Essa "população em perigo" e que necessita de "prevenção" aos riscos geralmente é identificada com a população com menor recurso financeiro, ou considerada pobre, conforme também aponta Vieira (2012, p. 108): "Correlaciona-se assim uma pobreza identitária e uma noção de risco naturalizada".

A partir dessas premissas, uma série de dispositivos disciplinares e de controle foi empregada para atuar inclusive sobre aquilo que essas classes podem vir a ser, como afirma Foucault (2005b), um controle das virtualidades. Os mecanismos disciplinares do corpo e os mecanismos regulamentadores da população articulam-se uns aos outros em torno da noção de risco, a qual se apresenta então como estratégia de governamentalidade.

Nesse contexto, não é de espantar que as trabalhadoras do Suas reivindiquem receber adicional de insalubridade a seus salários. Um motivo claro é a precarização do processo de trabalho e dos salários, mas essa reivindicação parece estar permeada pela compreensão de que as usuárias podem ser perigosas e trazer riscos para os profissionais. Nesse bojo, Vieira (2012) salienta que há um discurso heterodeclarado acerca da pobreza produtor de um quadro identitário, obscurecendo todas as demais produções tecidas no cotidiano de uma parcela da população. Perante essas afirmativas, apresenta-se então como desafio a desnaturalização das noções de pobreza, desigualdade e risco.

Lazzarato (2012) afirma que a lógica neoliberal joga com as desigualdades porque, de fato, é a partir delas que se governa. Não se almeja nem a redução nem a extinção das desigualdades: "A sociedade neoliberal vive bem com uma certa taxa de precariedade, de insegurança, de desigualdade, de pobreza, tal como as sociedades disciplinares admitiam naturalmente uma certa taxa de ilegalismo que elas próprias tinham 
criado" (Lazzarato, 2012, p. 50). A chamada pobreza no neoliberalismo não está ligada à falta de desenvolvimento, muito menos é o sintoma de um atraso que o crescimento econômico irá reabsorver: ela é criada e mantida com objetivos ligados à governamentalidade (Lazzarato, 2012).

Outro ponto que merece destaque no âmbito da atuação nos Cras são as intervenções que visam a higienização da população considerada vulnerável ou em risco. As investidas para a higienização dessa população são mais um dispositivo disciplinar e biopolítico. A higienização é um dos fatores que levam uma família a ser ou não considerada em vulnerabilidade.

\section{A preocupação com a higienização dos "vulneráveis" na Política de Assistência Social}

Seja no momento da visita domiciliar, seja nos momentos dos atendimentos, a higienização é um assunto que frequentemente entra em pauta nos Cras. Vários são os prontuários de famílias em que estão registradas informações sobre a higiene da casa e dos integrantes da família. Diversos foram os momentos em que as profissionais orientaram famílias sobre a higienização da casa. Uma trabalhadora do Cras certa vez contou que não foi bem recebida por uma família em uma visita domiciliar. Segundo ela, um componente da família dissera: "Vocês vieram aqui para saber se minha casa está limpa? Para me ensinar a limpar a casa? Não precisamos disso!". Podemos observar nesse caso tanto práticas de resistência quanto de controle operando. Percebemos por parte da pessoa que recebe a visita a afirmação de determinado modo de vida e a recusa a certas práticas de controle que ditam modelos de organização da casa. Uma recusa em aceitar que alguém deve ditar o modo de viver a outrem. Essas práticas de resistência e controle imbricam-se compondo a cena mencionada. Será possível realizar visitas domiciliares sem impor determinados padrões de higiene? Como produzir instrumentos de atuação que construam modos de vida dignos sem a pretensão de submetê-los ou julgá-los?

Na cena apresentada, vemos que são práticas de governo e de resistência pelo viés da higienização. Mas por que a preocupação com a higiene é apresentada de forma tão natural? Conforme aponta Corbin (1987), nos séculos XVIII e XIX na Europa, hábitos de higiene doméstica se fortaleceram e posteriormente se tornaram a "higiene da família". Esse processo, unido ao desdobramento da higiene pessoal, produziu uma exaltação da vida no espaço privado do lar em detrimento do espaço público. Foram tecidos novos modos de habitar a casa e a cidade, vinculados a uma noção de medicalização do espaço privado. Esses hábitos de higiene eram disseminados com objetivos ligados principalmente à moralização: “O imperativo do 'limpo em ordem', a aprendizagem da limpeza revelam seus objetivos múltiplos. $\mathrm{O}$ objetivo moralizador e a necessária compressão dos instintos insinuam-se onde, até então, se tratava de desinfecção" (Corbin, 1987, p. 144). O autor (Corbin, 1987, p. 185) sinaliza que nesse contexto a 
estratégia higienista assimilou simbolicamente a desinfecção à submissão, posto que "[...] tornar inodoro o proletário poderia instituir a disciplina e o trabalho".

Essas tentativas de imposição de valores higienistas não se deram de modo harmonioso. As autoridades higienistas da época sofreram vários reveses em suas tentativas de implantar uma nova ordem. Motins eram realizados contrapondo-se às novas regras de desodorização, limpeza e organização social (Corbin, 1987). Por sua vez, Donzelot (1986, p. 46), afirma que foi com o intuito de promover a preservação da sociedade liberal por meio da adaptação dos indivíduos a esse regime que os higienistas incitaram o Estado a intervir pela norma na esfera do direito privado, no século XIX. Rago (1985) também sinaliza um momento em que a medicina passou a incluir em suas pautas a questão social e a construção de novos saberes e controle particularmente sobre a criança e sobre a mulher, no século XIX, e intensificando-se no século XX. De acordo com a autora, equipes médicas eram formadas para orientar gratuitamente as mães pobres sobre a higiene infantil (Rago, 1985). As famílias pobres eram os principais alvos, já que as mulheres dessas famílias eram responsabilizadas pelas altas taxas de mortalidade das crianças devido à sua ignorância e inobservância das morais de higiene (Rago, 1985). Essa situação justificava a rígida interferência da medicina no controle cotidiano dos pobres.

De acordo com a autora, a grande preocupação com a situação das crianças era na verdade uma preocupação econômica, na medida em que essas passam a ser entendidas como "corpo produtivo, futura riqueza das nações" (Rago, 1985, p. 121). E também uma preocupação política, já que fornecer assistência médica e assistência à infância evitaria formar, entre a população, rebeldes e desajustados. A mesma autora afirma que "os perigos detectados nos espaços públicos são transferidos, pela imaginação dos médicos, para a habitação insalubre e suja do pobre [...]" (Rago, 1985, p. 174). Este último passa, então, a ser alvo de várias intervenções com objetivo de eliminar o risco que significava para a sociedade burguesa.

As preocupações com as instalações consideradas insalubres dos pobres eram de teor econômico e político que visava o controle das populações para a melhor condução de seu conjunto. A higiene no interior das famílias precisava, portanto, ser disseminada e até mesmo imposta. Donzelot (1986) aponta que a construção de um modelo familiar que privilegie a higiene permite de modo mais satisfatório a manutenção da ordem pública.

Ressalvamos que não pretendemos desconsiderar os benefícios das práticas de higiene que contribuem para o aumento da expectativa de vida da população, ajudando na prevenção de doenças e sofrimentos. Mas não se pode negar que historicamente certo modo de se relacionar com a higiene foi utilizado como forma de domesticar a população, principalmente a população pobre, com objetivos ligados à governamentalidade, enaltecendo determinados modos de vida e desqualificando outros. A máxima popular "sou pobre, mas sou limpinho" vigora ainda hoje e opera desqualificando os modos de vida principalmente da população pobre. A preocupação com a higienização da casa do 
pobre diz respeito a um imperativo de domesticação e de integração à ordem e à moralidade vigente, de submissão.

Mas, como visto, nem todos se submetem, alguns gritam e questionam intervenções naturalizadas no âmbito da assistência social. Ouvir esses gritos e até mesmo sussurros é exercício cotidiano na construção de novas práticas nesse campo de atuação profissional. Práticas de silenciamento desses gritos ou sussurros também estão presentes na assistência social.

\section{Conclusão}

Pode-se, portanto, concluir que a condição precária de vida em que se encontra uma parcela da população deve continuar sendo fator de indignação, mobilização e luta por vida digna. Pois o que é considerado pobreza não diz respeito a um atributo interior ou é culpa dos sujeitos, mas sim a uma produção social datada historicamente que submete e mantém determinados grupos em condições de vida degradantes. A naturalização das noções de vulnerabilidade, risco, pobreza e desigualdade leva à sua perpetuação.

Por tudo isso, consideramos necessário questionar o que temos produzido no âmbito da assistência social e apontar que é possível criar ações que escapem às produções regulamentadoras e fiscalizadoras. Compreender como se dão os mecanismos de controle diz respeito a um processo de resistência que abre caminhos para a construção de estratégias de como frustrá-los. E essas construções têm arranjos de infinitas configurações.

O objetivo deste artigo consistiu na problematização da produção da vulnerabilidade e da higienização da vida dos pobres por meio da Política de Assistência Social. Ressaltamos nesse processo as práticas de controle da vida e de resistência a essas produções de vulnerabilização e higienização. Entendemos que as práticas de profissionais e usuários, arguindo as engrenagens desses processos de domesticação e controle da vida dos mais pobres, contribuem para desnaturalizar práticas hegemônicas que desejam vidas fracas e assépticas. O cotidiano repleto de disputas nos jogos de poder mostra a potência e a pluralidade das práticas na assistência social. Longe de traçar destinos ou criar modelos de atuação, pretendeu-se aqui abrir caminhos para novas problematizações e novas produções que estejam comprometidas com a produção de vidas dignas.

\section{Referências}

Brasil. (2004). Resolução $n^{\circ} 145$, de 15 de outubro de 2004. Plano Nacional de Assistência Social (PNAS). Diário Oficial da União. Brasília, DF, 28 out. 2004.

Castel, R. (2005). A insegurança social: o que é ser protegido? Petrópolis: Vozes. 
Corbin, A. (1987). Saberes e odores: o olfato e o imaginário social nos séculos dezoito e dezenove. São Paulo: Companhia das Letras. 367p.

Cruz, L. R. \& Hillesheim, B. (2013). Por uma crítica das práticas psicológicas na assistência social: tantas coisas podem ser mudadas... In A. L. Brizola, A. V. Zanella, \& M. Gesser (Org.). Práticas sociais, políticas públicas e direitos humanos. (pp. 181193). Florianópolis: Abrapso - NUPPE/CFH/UFSC.

Donzelot, J. (1986). A polícia das Famílias. (2 ed). Rio de Janeiro: Edições Graal. 209p.

Foucault, M. (2005a). Aula de 17 de março de 1976. In M. Foucault. Em defesa da sociedade: curso no Collége de France (1975-1976). (pp. 284-315). São Paulo: Martins Fontes.

Foucault, M. (2005b). A verdade e as formas jurídicas. Rio de Janeiro: NAU Editora. $158 p$.

Foucault, M. (2006a). A escrita de si. In: M. Foucault. Ética, sexualidade, política. Coleção Ditos e Escritos v. V. (2 ed); (pp. 144-162). Rio de Janeiro: Forense Universitária.

Foucault, M. (2006b). Poder e saber. In: M. B. da Motta (Org.). Estratégia, poder-saber. Coleção Ditos e Escritos v. IV. (2 ed). (pp. 223-240) Rio de Janeiro: Forense Universitária.

Foucault, M. (2008a). Aula de 25 de janeiro de 1978. In M. Foucault. Segurança, território e população: curso dado no Collége de France (1977-1978). (pp. 73116). São Paulo: Martins Fontes.

Foucault, M. (2008b). Aula de $1^{\circ}$ de fevereiro de 1978. In M. Foucault. Segurança, território e população: curso dado no Collége de France (1977-1978). (pp. 117153). São Paulo: Martins Fontes.

Foucault, M. (2010a). Conversa com Michel Foucault. In M. B. da Motta (Org.). Repensar a política. Coleção Ditos e Escritos v. VI. (pp. 289-347). Rio de Janeiro: Forense Universitária.

Foucault, M. (2010b). O sujeito e o poder. 1982. In L. H. Dreyfus \& P. Babinow. Michel Foucault: uma trajetória filosófica - para além do estruturalismo e da hermenêutica. Rio de Janeiro: Forense Universitária. 348p.

Lazzarato, M. (2012). O governo das desigualdades: crítica da insegurança neoliberal. Disponível em: http://zillis.webnode.com/products/o-governo-das-desigualdades1/

Lourau, R. (2004). Implicação e sobre implicação. In S. Altoé (Org.). René Lourau: analista institucional em tempo integral. São Paulo: Hucitec. 287p.

MDS. Ministério do Desenvolvimento Social e Combate à Fome. (2013). Concepção de Convivência e Fortalecimento de Vínculos. Brasília, DF: MDS.

Rago, M. (1985). Do cabaré ao lar: a utopia da cidade disciplinar: Brasil 1890-1930. Rio de Janeiro: Paz e Terra. 209p. 
Silva, R. N. (2005). A invenção da psicologia social. Petrópolis: Vozes.

Siqueira, K. O. M. \& Lino, M. V. (2013). Assistência social e biopoder: produzindo "vulnerabilidades", prevenindo "riscos" e normalizando as formas de viver. Mnemosine, 9(2), 35-53. Recuperado em 28 Julho, 2017, de www.mnemosine.com.br.

Vieira, L. F. D. (2012). Vida no Forte São João e a tecedura de políticas: acompanhando a produção de redes. (Dissertação de mestrado não publicada). Universidade Federal do Espírito Santo, BR.

Submissão: 6.12.2016

Aceitação: 20.6.2017 